\title{
The Origin of Lecithodesmus (Digenea: Campulidae) Based on ND3 Gene Comparison
}

M. Fernández, F. J. Aznar, J. A. Raga, and A. Latorre`, Instituto Cavanilles de Biodiversidad y Biología Evolutiva, Departamento de Biología Animal, and *Departamento de Genética, Universitat de València, Dr. Moliner, 50, 46.I00-Burjassot, Valencia, Spain

ABSTRACT: Species of Lecithodesmus (Campulidae) occur almost exclusively in baleen whales throughout a wide geographical distribution. Other campulids occur only in odontocetes and, secondarily, in pinnipeds and the sea otter. Therefore, the ancestor of Lecithodesmus might have either cospeciated with mysticetes during the early divergence of mysticete and odontocete cetaceans or originated later via host switching. We evaluate both possibilities based on a phylogenetic analysis. The ND3 mitochondrial gene sequence of a species of Lecithodesmus was included in a previous partial molecular phylogeny of the Campulidae. Fasciola hepatica and Dicrocoelium dendriticum were used as outgroups. Maximum parsimony, neighbor-joining, and maximum likelihood methods indicated a nonbasal position of Lecithodesmus sp. in the tree, suggesting that the ancestor of Lecithodesmus colonized mysticetes from campulids of odontocetes. This result emphasizes the importance of host-switching processes in the development of the helminth fauna of marine vertebrates, as previously suggested.

Members of the Campulidae (Digenea) occur extensively in cetaceans and, secondarily, in pinnipeds and the sea otter (Fernández, Aznar et al., 1998). Of the 8 genera included within this family, only species of Lecithodesmus infect mysticete cetaceans; in fact, they seem to have a remarkable specificity to baleen whales (Fernández, 1996; Fernández, Aznar et al., 1998). Species of this genus have been found, throughout a vast geographical region, in 8 of the 9 mysticete species analyzed thus far for helminth parasites (Fernández, 1996). Only 5 specimens of Lecithodesmus nipponicus have been collected in odontocete cetaceans (Yamaguti, 1942). As the Mysticeti split early in the phylogeny of the Cetacea (see the most recent phylogenetic hypothesis by Milinkovitch [1997]), the question arises over whether the ancestor of Lecithodesmus might have cospeciated with mysticetes. Otherwise, Lecithodesmus should have originated later via host switching from campulids of odontocetes. In the present paper, we obtained the sequence of a mitochondrial gene, the ND3 (subunit 3 of the nicotinamide adenine dinucleotide dehydrogenase) of an unidentified species of Lecithodesmus, and a phylogeny was inferred also using the sequences of other campulids (Fernández, Aznar et al., 1998) in order to test these 2 alternative hypotheses.

Worms were obtained from a minke whale, Balaenoptera acutorostrata, in the Norwegian Sea and preserved in $70 \%$ ethanol. The DNA extraction and amplification procedures are described in Fernández, Aznar et al. (1998). However, a new forward primer was designed for PCR amplification from our catalogued ND3 campulid sequences (accession numbers AF034551, AF034552, and AF034554-57): 5'-GCTTAATTKKTAAAGCYTTGRATTCTTACT-3' . Reverse primer sequence is 5'-CTACTAGTCCCACTCAAC(G/A)TAACC(T/ C)T-3' (primer 4 in Fernández, Aznar et al. [1998]). Amplification reactions contained $5 \mu \mathrm{l}$ of DNA, $200 \mu \mathrm{M}$ of dNTPs, $0.4 \mu \mathrm{M}$ of each primer, and 2.5 units of Taq DNA polymerase (Amersham, Pharmacia, Buckinghamshire, U.K.), in a final volume of $50 \mu \mathrm{l}$. DNA was denatured for $5 \mathrm{~min}$ at $95 \mathrm{C}$. A total of 35 cycles were performed with the GeneAmp 2400 System, each cycle consisting of 3 steps: $95 \mathrm{C}$ for $30 \mathrm{sec}, 50 \mathrm{C}$ for 30 sec, and $72 \mathrm{C}$ for $50 \mathrm{sec}$. A final step was carried out at $72 \mathrm{C}$ for $7 \mathrm{~min}$. The PCR product was cloned into pGEM-T Easy vector (Promega). Sequencing was performed on both strands of 2 clones with the AmpliTaqF Dye Deoxy Terminator Cycle Sequencing kit (Perkin-Elmer, Foster City) and the 373 automated DNA sequencer, using T3 and SP6 universal primers.

Sequences of campulid species plus 2 outgroups, Dicrocoelium dendriticum and Fasciola hepatica, were aligned with CLUSTAL V program (Higgins et al., 1992) and analyzed with maximum parsimony (MP) with exhaustive search using PAUP (Swofford, 1993), neighbor-joining (NJ) using MEGA version 1.01 (Kumar et al., 1993) and maximum likelihood (ML) using PAML version 2.0 (Yang, 1999). The ML tree was obtained under the HKY model of nucleotide substitution and rate variation among sites using an approximate gamma distribution (Hasegawa et al., 1985). For the ML method, tests of alternative topologies were carried out using the RELL technique (resampling estimated log likelihood) (Kishino and Hasegawa, 1989; Kishino et al., 1990) Genetic distances were estimated according to Kimura's 2-parameter model (Kimura, 1980) (Table I). In addition, sequences were translated into amino acids using the $F$. hepatica mitochondrial DNA genetic code. Dayhoff PAM distances (Dayhoff et al., 1978) were then calculated and subjected to NJ analysis using Phylip version 3.5. In MP and NJ, we employed, alternatively, transversions only (ingroup + outgroups) that accumulate at slower rates than transitions and transversions + transitions within the ingroup species because transitions were not saturated within the ingroup (see Fernández, Aznar et al. [1998] for details). The statistical confidence of a particular cluster of sequences was evaluated by the bootstrap procedure (1,000 replicates). Bootstrap values higher than $70 \%$ were considered significant (Hillis and Bull, 1993).

TABLE I. Nucleotide distances of a Kimura 2-parameter model between pairs of species.*

\begin{tabular}{lccccccccc}
\hline & CO & ZA & HT & OF & OR & NG & L & FH & DD \\
\hline CO & - & & & & & & & & \\
ZA & 0.133 & - & & & & & & & \\
HT & 0.228 & 0.184 & - & & & & & & \\
OF & 0.117 & 0.168 & 0.244 & - & & & & & \\
OR & 0.124 & 0.160 & 0.248 & 0.012 & - & & & & \\
NG & 0.202 & 0.225 & 0.265 & 0.201 & 0.204 & - & & & \\
L & 0.139 & 0.114 & 0.209 & 0.167 & 0.160 & 0.220 & - & & \\
FH & 0.318 & 0.310 & 0.349 & 0.349 & 0.349 & 0.413 & 0.354 & - & \\
DD & 0.577 & 0.600 & 0.627 & 0.603 & 0.590 & 0.636 & 0.622 & 0.576 & - \\
\hline
\end{tabular}

* Species name abbreviations: CO, Campula oblonga; ZA, Zalophotrema atlanticum; HT, Hadwenius tursionis; OF, Orthosplanchnus fraterculus; OR, Oschmarinella rochebruni; NG, Nasitrema globicephalae; L, Lecithodesmus sp.; FH, Fasciola hepatica; DD, Dicrocoelium dendriticum. 


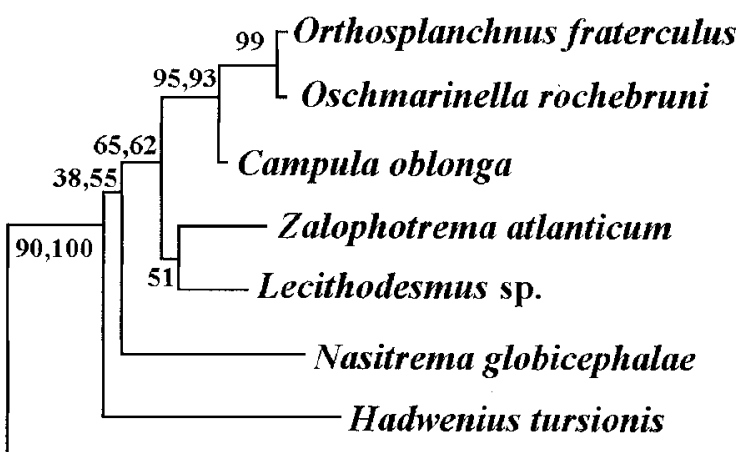

Fasciola hepatica

Dicrocoelium dendriticum

FIgURE 1. Phylogenetic tree of the Campulidae inferred from transversions in the ND3 gene using neighbor-joining distances (NJ) and

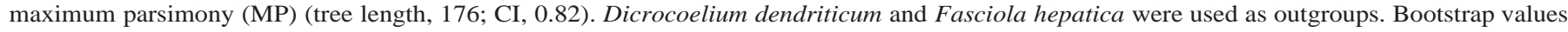
are shown at internodes. Left to right: NJ, MP. A single number indicates that both methods rendered the same value.

Alignment of the ND3 sequences was 363 bases long, including gaps (variable positions $=215$, informative sites $=98$, alignment not shown). All the sequences displayed phylogenetic signal. The initiation codon for Lecithodesmus sp. was GTG, as in other campulid species. Regardless of the method applied, Lecithodesmus sp. appeared in a nonbasal position within the cladogram of the Campulidae. Hadwenius tursionis occupied the basal position in most reconstructions. In fact, the nucleotide distances between $H$. tursionis and the rest of campulids was always higher than those between Lecithodesmus and the rest of campulids (Table I). Both NJ and MP methods with transversions (ingroup + outgroups) revealed the same tree topology, i.e., Lecithodesmus sp. and Zalophotrema atlanticum formed a clade, although supported by a low bootstrap value (Fig. 1). Using transitions + transversions (ingroup), the bootstrap $50 \%$ majority-rule consensus parsimony tree produced a polytomy (tree not shown), whereas the NJ rendered a tree to-

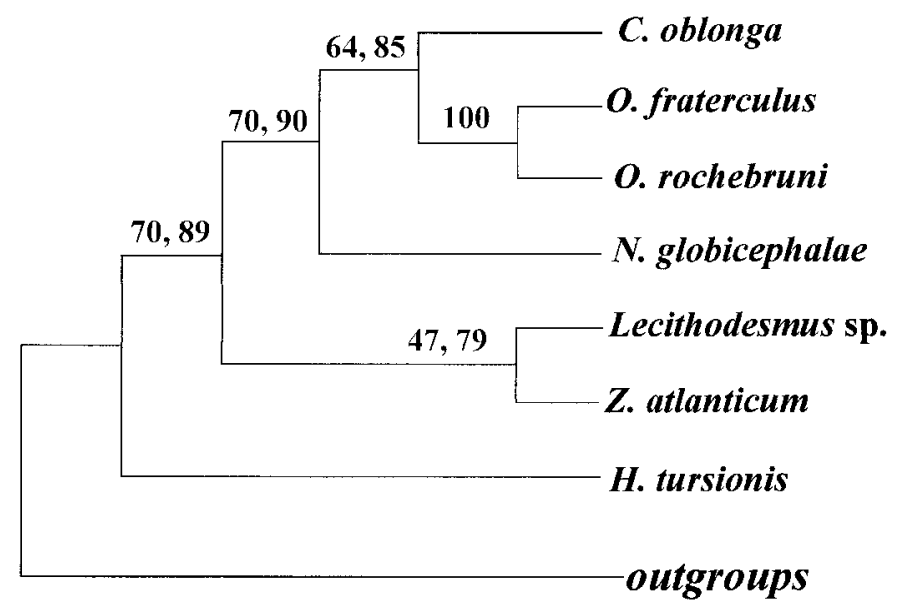

FIgURE 2. Phylogenetic tree of the Campulidae inferred from transitions and transversions and amino acid sequences within the ingroup taxa of the ND3 gene. Neighbor-joining distances method was used. Bootstrap values are shown at internodes. Left to right: transitions and transversions, amino acids sequences. A single number indicates that both methods rendered the same value. The tree has been rooted according to the topology in Figure 1 that included the outgroup taxa. pology slightly different from that in Figure 1. Again, the clade Lecithodesmus sp.-Z. atlanticum had a low bootstrap value (Fig. 2). However, a significant bootstrap value was obtained for this clade with the amino acid sequence analysis (Fig. 2). The ML tree was obtained using $F$. hepatica as the only outgroup in order to avoid the distortion produced by the great nucleotide distances between the second outgroup, D. dendriticum, and the rest of species (Table I; see Fernández, Aznar et al. [1998] for details). The ML tree (log likelihood = $-1,444.26)$ was consistent with those obtained using MP and distance methods (Fig. 3). The same analysis forcing Lecithodesmus sp. as the basal taxon resulted in a log likelihood of $-1,452.51$. The RELL method assigned a $95.12 \%$ bootstrap support for the ML tree and $4.38 \%$ to the alternative topology,

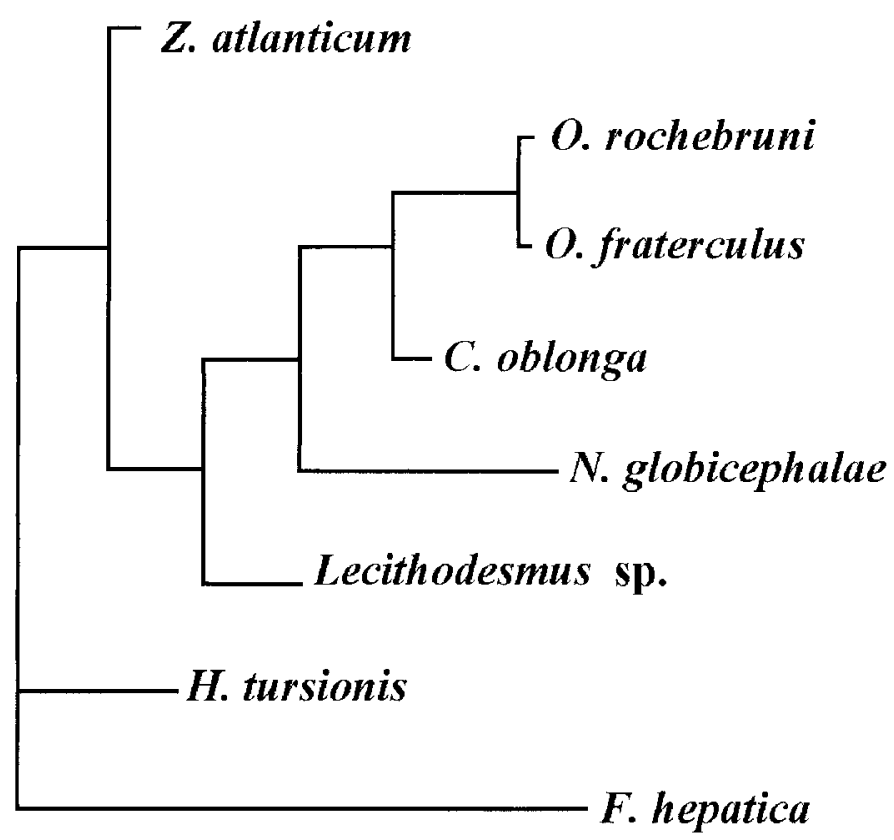

FIgURE 3. Phylogenetic tree of the Campulidae inferred from ND3 sequences using the maximum likelihood method. 
thus allowing us to reject the hypothesis of basality for Lecithodesmus sp. in the Campulidae tree.

As to the relationships among the rest of campulids, none of the above results essentially modify the cladograms obtained in a previous study by Fernández, Aznar et al. (1998).

Overall, our analyses support the hypothesis that species of Lecithodesmus originated from campulids of odontocetes, confirming the importance of colonization in the origin and diversification of these digeneans: the Campulidae putatively originated from digeneans infecting fish, and pinnipeds apparently acquired campulids from toothed whales via 2 independent host-switching events (Fernández, Aznar et al., 1998; Fernández, Littlewood et al., 1998). Colonization has also been implicated in the origin of parasitic taxa in many other marine vertebrates, e.g., Alcataenia (Cestoda) in Holarctic marine birds (Hoberg, 1986), tetrabothriids (Cestoda) in marine homeotherms (Hoberg et al., 1997), Anophryocephalus (Cestoda) in arctic pinnipeds (Hoberg, 1995), and pronocephalids in freshwater turtles, fish, and the marine iguana (Pérez Ponce de León and Brooks, 1995a, 1995b).

The likelihood of a successful colonization depends on the probability of encounter and the physiological and immunological compatibility between the parasite and the potential new host. Campulids are food-transmitted parasites and, therefore, the odontocete-to-mysticete host switching had to require predictable long-term trophic associations between these hosts (see Hoberg, 1987). Whereas toothed whales feed mainly on fish, squid, or both, the diet of baleen whales varies depending on the species; some are entirely planctivorous, whereas others prey mostly upon fish. Unfortunately, we do not know how contacts might have proceeded because no life cycle of any campulid has been demonstrated. Attributes of miracidia are indicative of an indirect cycle, involving 1 or more intermediate hosts (Dailey, 1985). The widespread occurrence of campulids in hosts that feed exclusively on fish or squid suggests that these prey may act as second intermediate or paratenic hosts. In any case, frequent contacts would have led campulids to break the compatibility filter eventually, becoming adapted to baleen whales.

We thank Paul Aspholm for providing material for this work and Fernando González for analysis assistance. Computer analyses and automated sequencing were carried out using the "Servei de Bioinformàtica" and the S.C.S.I.E. of the University of Valencia, Spain, respectively. F.J.A. benefits from a PDF from the Ministerio de Educación y Ciencia (M.E.C.) (Spain). This work was supported by grant PB96-0793 and PB96-0801 from DGES (M.E.C., Spain) to A.L. and J.A.R., respectively, a grant from the Iberoamerican Co-operation Institute of the Spanish Government to M.F., F.J.A., and J.A.R. Nucleotide sequence of Lecithodesmus sp. is available in the EMBL, GenBankTM, and DDJB databases under the accession number AF123439.

\section{LITERATURE CITED}

DAiley, M. D. 1985. Diseases of Mammalia: Cetacea. In Diseases of marine animals, Vol. IV, part 2, O. Kinne (ed.). Biologische Anstalt Helgoland, Hamburg, Germany, p. 805-847.

Dayhoff, M. O., R. M. Schwartz, and B. C. Orcutt. 1978. A model of evolutionary change in proteins. Atlas of Protein Sequence and Structure 5: 345-352.

FERNÁNDEZ, M. 1996. Estudio de la filogenia y biogeografía de la familia Campulidae Odhner, 1926 (Trematoda: Digenea). Doctoral Thesis. Universitat de València, Valencia, Spain, 206 p.

- F. J. Aznar, A. Latorre, And J. A. Raga. 1998. Molecular phylogeny of the families Campulidae and Nasitrematidae (Trematoda) based on mtDNA sequence comparison. International Journal for Parasitology 28: 767-775.

- D. T. J. Littlewood, A. Latorre, J. A. Raga, And D. RollinSON. 1998. Phylogenetic relationships of the family Campulidae (Trematoda) based on 18S rRNA sequences. Parasitology 117: 383-391.

Hasegawa, M., H. Kishino, AND T. Yano. 1985. Dating of the humanape splitting by a molecular clock of mitochondrial DNA. Journal of Molecular Evolution 22: 160-174.

Higgins, D. G., A. J. Bleasby, and R. Fuchs. 1992. ClustalV-improved software for multiple sequence alignment. Computer Applications in the Biosciences 8: 189-191.

Hillis, D. M., AND J. J. Bull. 1993. An empirical test of bootstrapping as a method for assessing confidence in phylogenetic analysis. Systematic Biology 42: 182-192.

HoberG, E. P. 1986. Evolution and historical biogeography of a parasite-host assemblage: Alcataenia spp. (Cyclophyllidea: Dilepididae) in Alcidae (Charadriiformes). Canadian Journal of Zoology 64: $2576-2589$.

. 1987. Recognition of larvae of the Tetrabothriidae (Eucestoda): Implications for the origin of tapeworms in marine homeotherms. Canadian Journal of Zoology 65: 997-1000.

- 1995. Historical biogeography and modes of speciation across high latitude seas of the Holarctic: Concepts for host-parasite coevolution among the Phocini (Phocidae) and Tetrabothriidae (Eucestoda). Canadian Journal of Zoology 73: 45-57.

, J. Mariaux, J. L. Justine, D. R. Brooks, and P. J. Weekes. 1997. Phylogeny of the orders of the Eucestoda (Cercomeromorphae) based on comparative morphology: Historical perspectives and a new working hypothesis. Journal of Parasitology 83: 11281147.

KimuRA, M. 1980. A simple method for estimating evolutionary rate of base substitution through comparative studies of nucleotide sequences. Journal of Molecular Evolution 16: 111-120.

Kishino, H., AND M. Hasegawa. 1989. Evaluation of the maximum likelihood estimate of the evolutionary tree topologies from DNA sequence data, and the branching order in Hominoidea. Journal of Molecular Evolution 29: 170-179.

- T. Miyata, And M. Hasegawa. 1990. Maximum likelihood inference of protein phylogeny and the origin of chloroplasts. Journal of Molecular Evolution 31: 151-160.

Kumar, S., K. Tamura, and K. Nei. 1993. MEGA, molecular evolutionary genetics analysis, version 1.01. Institute of Molecular Evolutionary Genetics, The Pennsylvania State University, State University, Pennsylvania, $130 \mathrm{p}$.

Milinkovitch, M. C. 1997. The phylogeny of whales: A molecular approach. In Molecular genetics of marine mammals, A. E. Dizon, S. J. Chivers, and W. F. Perrin (eds.). Society for Marine Mammalogy, special publication 3: 317-338.

Pérez Ponce de León, G., AND D. R. Brooks. 1995a. Phylogenetic relationships of the genera of the Pronocephalidae Looss, 1902 (Digenea: Paramphistomiformes). Journal of Parasitology 81: 267277.

- 1995b. Phylogenetic relationships among the species of Pyelosomum Looss, 1899 (Digenea: Pronocephalidae). Journal of Parasitology 81: 278-280.

SwOFFORD, D. L. 1993. PAUP: Phylogenetic analysis using parsimony, version 3.1. Illinois Natural History Survey, Illinois, 257 p.

Yamaguti, S. 1942. Studies on the helminth fauna of Japan. Part 40. Three new species of trematodes from the bile ducts of marine mammals. Transactions of the Biogeographical Society of Japan 3/ 4: $399-407$.

YANG, Z. H. 1999. PAML: Phylogenetic analysis by maximum likelihood, version 2.0. University College, London, $36 \mathrm{p}$. 